\title{
Ebeveynleri Boşanmış ve Boşanmamış Ergenlerin Yılmazlık Düzeyleri ile Algıladıkları Sosyal Destek Düzeyleri*
}

\author{
Enes GÜNEY ${ }^{1}$ (iD), Süleyman Barbaros YALÇIN ${ }^{2}$ (iD)
}

${ }^{1}$ Milli Eğitim Bakanlı̆̆l, terapist70@gmail.com

${ }^{2}$ Necmettin Erbakan Üniversitesi, Konya, Türkiye, barbarosyl@gmail.com

\begin{tabular}{|c|c|}
\hline Makale Bilgileri & ÖZ \\
\hline $\begin{array}{l}\text { Makale Geçmişi } \\
\text { Geliş: } 30.09 .2020 \\
\text { Kabul: 07.12.2020 } \\
\text { Yayın: } 29.12 .2020 \\
\text { Anahtar Kelimeler: } \\
\text { Yılmazlık } \\
\text { Sosyal Destek } \\
\text { Ergenlik }\end{array}$ & 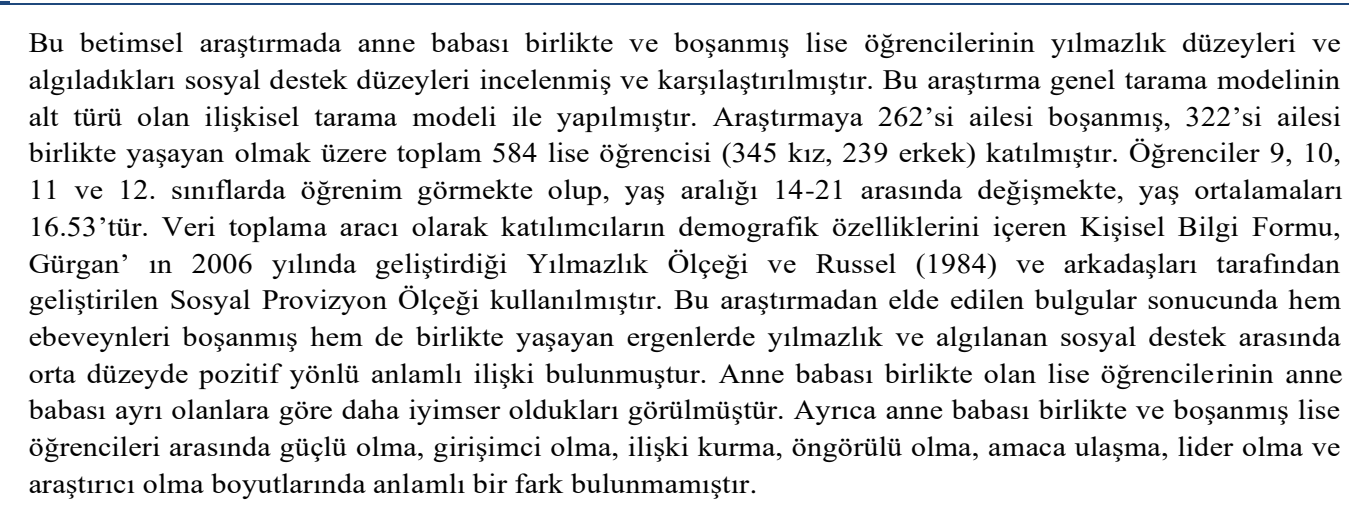 \\
\hline
\end{tabular}

\section{The Resilience Levels and Perceived Social Support Levels of Adolescents whose Parents Are Divorced and Not Divorced}

\begin{tabular}{|c|c|}
\hline Article Info & ABSTRACT \\
\hline $\begin{array}{l}\text { Article History } \\
\text { Received: } 30.09 .2020 \\
\text { Accepted: } 07.12 .2020 \\
\text { Published: } 29.12 .2020 \\
\text { Keywords: } \\
\text { Resilience } \\
\text { Social Support } \\
\text { Adolescent }\end{array}$ & $\begin{array}{l}\text { In this descriptive study, we compared the resilience levels of high schools whose parents are divorced to } \\
\text { those whose parents together and examined their perceived social support levels. This study has been carried } \\
\text { out with relational screening model which is a submodel of general screening model. In total, } 584 \text { students } \\
\text { ( } 345 \text { female, } 239 \text { male) participated the study and } 262 \text { of them have divorced parents and } 322 \text { of them have } \\
\text { family which lives together. Students study in } 9 \text { th, } 10 \text { th, } 11 \text { th and } 12 \text { th grades, the age range varies between } \\
14-21 \text {, their average age is } 16.53 \text {. As a data collection tool, resilience scale which is developed by Gurgan in } \\
2006 \text { and social provision scale which is developed by Russel et al. (1984) have been used. In consequence of } \\
\text { the findings which have been obtained from this study, a medium-level, positive and meaningful relation } \\
\text { between the resilienece and social support both in adolescents whose parents are divorced and in adolescents } \\
\text { whose parents are together has been founded out. It has been seen that the high school students whose parents } \\
\text { are together are more optimistic than the ones whose parents are divorced. Also, it is not found significant } \\
\text { difference between the high school students whose parents are together and divorced in terms of being strong, } \\
\text { entrepreneurial, establishing relationships, being predictive, reaching the goal, being a leader and being a } \\
\text { researcher. }\end{array}$ \\
\hline
\end{tabular}

*Ebeveynleri Boşanmış ve Boşanmamış Ergenlerin Yılmazlık Düzeyleri ile Algıladıkları Sosyal Destek Düzeyleri" başlıklı çalışma Enes Güney'in aynı başlıkla tamamladığı yüksek lisans tezinden üretilmiştir.

"This article is licensed under a Creative Commons Attribution-NonCommercial 4.0 International License (CC BY-NC 4.0)"

Atıf/Citation: Güney, E. \& Yalçın, S. B. (2020). Ebeveynleri Boşanmış ve Boşanmamış Ergenlerin Yılmazlık Düzeyleri ile Algıladıkları Sosyal Destek Düzeyleri, Necmettin Erbakan Üniversitesi Ereğli Eğitim Fakültesi Dergisi, 2(2), 217-229. 


\section{GíRiş}

Bireyin gelişimi ele alındığında çevre ve kalıtımın büyük oranda etkisi olmakla beraber, kişilik ve karakter gelişimi kişinin yetiştiği sosyal çevre, içinde bulunduğu toplumun kültürü, biyolojik etkenler, fizyolojik yap1 ve yaşadığı psikolojik gelişimsel süreçlerin bütününden bahsetmek gerekir. Bu bağlamda her birey biriciktir, yaşantı deneyimleri, sosyal çevreleri, aile ve akrabalık yapıları, kişilik tipleri ve karakteristik özellikleri, geliştirmiş oldukları normlar birbirlerinden farklılık gösterecektir. Kişiliğin oluşumu ve karakter gelişimi açısından ele alındığında ilk sosyalleşme deneyimlerinin gerçekleştiği, ilk öğrenmelerin kazanıldığı aile büyük önem arz etmektedir. Bebeklik ve çocukluk gelişim dönemlerinde ailenin özellikle de annenin birey üzerinde psiko-sosyal gelişim açısından kritik önemi vardır; ilk çocukluk ve son çocukluk gelişim dönemlerini takip eden ergenlik dönemini ele aldığımızda bireyin fizyolojik, psikolojik, sosyal alanlarda yoğun değişim ve gelişimsel süreçler yaşadığı görülmektedir.

Kişiliği bireyin yaşadığı toplumun ekonomik ve sosyo kültürel koşulları desteklemekte ve etkilemektedir ayrıca bireyin yetiştiği ailenin yapısı, kardeş sayısı, ailenin ekonomik durumu içinde yaşadığı toplumun kültürü gibi sosyal etmenler bireyin getirdiği genetik faktörlerle etkileşim kurarak kişiliği oluşturur (Kırkıncıoğlu, 2003). Ergenlik dönemi çocukluk çağlarından bir yetişkin olmaya geçiş hazırlıklarını içeren ergenin fizyolojik psiko-sosyal ve bilişsel gelişim alanlarında, iç ve dış dünyasında değişimler yaşadığı bu değişimlere sağlıklı uyum sağlayabilmesi için aile ve çevre desteğine en fazla ihtiyaç duyduğu gelişimsel bir süreçtir (Arslan, 2009). Ergenlik döneminde her birey kendine özgü yaşam deneyimlerine sahip olmakla birlikte bu dönemdeki bireyler genel olarak yaşamlarının en zorlu ve değişken süreçlerini yaşamakta, ergen yetişkin olma yolunda ilerlediği bu süreçte kimlik karmaşası, uyum sorunları, çatışma durumları gibi gelişimsel süreçlerde sağlıklı kimlik oluşturma, olumsuz yaşam durumlarına başarılı bir şekilde uyum sağlama ve adaptasyon, problem çözme becerilerini geliştirme, esneklik, psikolojik sağlamlık, özdenetim, özsaygı gibi koruyucu faktörlerle sağlıklı kimlik bütünlüğünü geliştirmeye ve oluşturmaya çalışmaktadır (Ünüvar, 2012). Ergenlik dönemindeki birey çocukluk döneminin aksine zamanla aileden uzaklaşarak arkadaşlar ve sosyal çevreye daha yakınlaşmakta, bu dönemde yaşadığı hızlı gelişim ve değişimlere ayak uydurmak, büyüdüğünü ve bağımsız bir birey olduğunu hissettirmek özgür olduğunu kanıtlamak çabasında olmakla beraber bu süreçlere uyum sağlayabilmek için aile arkadaş ve çevresindeki diğer yetişkinlerden yoğun destek aramaktadır (Dülger, 2009).

Çocukların ve ergenlerin ileri yaşlarda, yaşayabilecekleri olumsuz yaşantı deneyimleri, riskli durumlar, travmatik olaylar gibi durumlar karşısında başarılı uyum ve adaptasyon sağlamalarına yönelik koruyucu, geliştirici çalışmalar ruh sağlığı uzmanları, sosyal çalışmacılar, psikolojik danışmanlar, sosyal bilimciler ve eğitimciler tarafından gerçekleştirilmektedir (Gizir, 2004). Yılmazlık koruyucu ve önleyici etkileri, bireylere gelişimsel yönden sunduğu katkıları, risk altındaki çocuklar ve ailelerine yönelik yürütülen psiko-sosyal çalışmaları desteklemesi açısından alanyazında her geçen gün popülaritesi artan bir kavramdır (Kumpfer, 1999; Öğülmüş, 2001; Olsson ve diğ., 2003; Gizir, 2004; Gürgan, 2006; Arman, 2009; Boran, Sürücü, Yılmaz, 2018; Özer, Deniz, 2014; Akman, Abasl1, Polat, 2018; Çiftçi Arıdağ, Ünsal Seydooğulları, 2019; Demir, Aliye, 2019). Yılmazlık, bireyin olumsuz ve stresli yaşam olaylarına, deneyimlere, başından geçen travmatik olaylara rağmen var olan zorlayıcı durumların üstesinden gelmesi; bireyin yaşanan olumsuz süreci beklenenden daha iyi yönetmesi, kriz anından başarılı bir şekilde çıkmasını sağlayan, normale dönebilme yeterliliğine sahip olmasıdır (Gürgan, 2006).

Peng ve arkadaşlarının (2012) tıp öğrencileriyle yapmış oldukları esneklikle ilgili çalışmanın bulgularına göre kız öğrencilerin yılmazlık düzeylerinin erkek öğrencilerin yılmazlık düzeyinden daha fazla olduğu görülmüştür. Öğrencilerin sınıf düzeyleri ile esneklik toplam puanları açısından anlamlı bir fark bulunamamıştır. Sonuçlar esnekliğin olumsuz yaşam olayları ve ruhsal sağlık sorunları üzerinde yumuşatıcı bir etkiye sahip olduğu hipotezini açıkça desteklemektedir. Ayrıca negatif olaylar, kişilik özellikleri, sosyal destek ve esneklik tüm Çin tıp öğrencilerinin ruh sağlığı sorunları ile ilişkili bulunmuştur. Bu çalışmada ele alınan yılmazlık ve yakından ilişkili olan diğer değişken sosyal destek ise başkaları tarafından kişinin 
psikolojik sağlığının korunması, kritik hayat olaylarına uyumun kolaylaşması ve gelişimin en uygun biçimde ortaya çıkması için sağlanan duygusal, fiziksel, bilgilendirici, araçsal ve parasal yardım olarak da tanımlayabiliriz (Dunst, Trivette, Cross, 1986).

12 ve 18 yaşlar arsındaki ergenlerde yılmazlık konusu 1990 ve 2000 y1lları arasında literatüre girmeye başlamıştır (Olsson ve diğ., 2003). Ülkemizdeki literatür incelendiğinde yılmazlık kavramının bireylerin yaşamında ve gelişimde sağladığı katkı yeni anlaşılmaya başlanmıştır. Bu nedenle yılmazlığ geliştirici çalışmaların çok eskilere dayanmadığı bu konuda yapılan ve gerçekleştirilen çalışmaların son yıllarda başladığı görülmüştür. Risk altında ve stresli yaşam koşulları içerisinde yetişen çocuk ve ergenlerin yaşamlarının ileri safhalarında yaşayacakları muhtemel olumsuzlukları önlemek ve koruyucu tedbirler almak amacıyla yılmazlık alanında çalışmalar yapma ihtiyacı ortaya çıkmıştır (Onat, 2010). Bu nedenle ergenlerde yılmazlık konusunun çalışılması, bu kavramın diğer kavramlarla ele alınması ve incelenmesinin yerinde olacağı düşünülmektedir. Gençlerde oluşabilecek ve olumsuz davranışları, yetersizlikleri ve hassasiyetleri betimlemek ve bunlara müdahale edebilmek adına ergenlerde y1lmazlık ve sosyal destek algısının incelenmesi önem arz etmektedir. Elde edilen bulgular neticesinde çocuklara, gençlere ve yetişkinlere sağlanan danışmanlık hizmetlerine de katkı sağlanabileceği düşünülmektedir.

$\mathrm{Bu}$ çalışmanın lise öğrencilerinin yılmazlık düzeyleri üzerinde algılanan sosyal desteğin etkileri açısından incelenerek katkı sağlayacağı düşünülmektedir. Bunun yanı sıra bu iki değişkenle gerçekleştirilen çalışmaların sınırlı olmasından dolayı, alana katkı sağlanacağı; bu çalışma sonucunda elde edilen verilerin çocuklara, ergenlere yönelik gerçekleştirilen önleyici ve koruyucu çalışmalarda ruh sağlığı çalışmalarına, psikolojik danışma ve rehberlik faaliyetlerine yol gösterici olacağı düşünülmektedir. Ayrıca bu araştırmadan elde edilen sonuçlar, lise öğrencilerinin yaşadığı zorlu yaşam sorunlarının belirlenmesi, psikolojik sorunlarının betimlenmesi, tespit edilen sorun ve problemlerin çözümü ve giderilmesinde, psikolojik destek veren uzmanlara, ailelere ve eğitimcilere de kaynak olacaktır. Ruh sağlığı uzmanlarının, öğretmenlerin ve ailelerin önleyici çalışmalarda bulunabilmelerine de kaynaklık edecektir.

\section{Araştırmanın Amacı}

$\mathrm{Bu}$ çalışmanın amacı, ebeveynleri boşanmış ve boşanmamış lise öğrencilerinin yılmazlık düzeyleri ile algıladıkları sosyal destek düzeyleri arasındaki ilişkinin incelenmesidir. Çalışmanın alt amacı lise öğrencilerinin ebeveynlerinin evli ya da boşanmış olma durumuna göre sosyal provizyon algılarında ve yılmazlık düzeylerinde farklılaşma olup olmadığını araştırmaktır

\section{YÖNTEM}

$\mathrm{Bu}$ betimsel araştırmada anne babası boşanmış ve anne babası birlikte olan lise öğrencileri, yılmazlık düzeyleri ve algıladıkları sosyal destek düzeyleri açısından incelenmiştir. Ayrıca bu araştırma ilişkisel tarama modeli kullanılarak gerçekleştirilmiştir

\section{Araştırma Modeli}

$\mathrm{Bu}$ betimsel araştırmada anne babası boşanmış ve anne babası birlikte olan lise öğrencileri, yılmazlık düzeyleri ve algıladıkları sosyal destek düzeyleri açısından incelenecektir. Ayrıca bu araştırma ilişkisel tarama modelinde gerçekleştirilmiştir. İlişkisel tarama modelleri, iki veya daha çok sayıdaki değişken arasında birlikte değişim varlığını ve /veya derecesini belirlemeyi amaçlayan araştırma modelleridir (Karasar, 2006).

\section{Çalışma Grubu}

$\mathrm{Bu}$ araştırmada çalışma grubu Karaman İlinde eğitim gören lise öğrencilerdir. Araştırmanın örneklemi 2014 yılında liselerde okuyan ebeveynleri birlikte ve boşanmış öğrenciler oluşturmaktadır. Araştırmaya 262'si ailesi boşanmış, 322'si ailesi birlikte yaşayan olmak üzere toplam 584 öğrenci (345 k1z, 239 erkek) katılmıştır. Öğrenciler 9 (173 öğrenci), 10 (161 öğrenci), 11(161 öğrenci) ve 12. (89 öğrenci) sınıflarda 
öğrenim görmekte olup, yaş aralığı 14-21 arasında değişmekte ve yaş ortalamaları 16.53’tür.

\section{Veri Toplama Araçları ve Süreçleri}

\section{Yılmazlık Ölçĕ̆i}

$\mathrm{Bu}$ araştırmada, Gürgan (2006) tarafından geliştirilen Yılmazlık Ölçeği veri toplama aracı olarak kullanılmıştır. Yılmazlık konusunda geliştirilen bu ölçek ilgili literatürün taranarak madde havuzunun oluşturulması, yabancı yayınlardaki ölçeklerin Türkçe'ye çevrilmesiyle oluşturulmuştur. Ölçek beşli likert formatında, 50 maddeden oluşmakta, 8 alt boyuttan oluşmakta ve ölçekten alınabilecek puan aralığ 50 ile 250 arasında değişmektedir. Ölçek sonucunda elde edilen puanların yüksek olması yılmazlık düzeyinin arttığını düşük olması yılmazlık düzeyinin azaldığını göstermektedir. Güvenirlik çalışmaları amacıyla bir ay arayla yapılan uygulamaların sonucunda korelasyon analizi.89 olarak bulunmuştur $(\mathrm{p}<.001, \mathrm{~N}=49$, $\mathrm{SS}=11.57, \mathrm{t}=-2.51$ ). Elde edilen bulgular ölçeğin kararlılı̆̆ için oldukça iyi bir sonuç olarak düşünülmektedir. İç tutarlılık uygulamaları sonucu Cronbach Alfa değeri sırasıyla .78 ve .87, geçerlik çalışması Cronbach Alfa değeri de .80 olarak bulunmuştur (Gürgan, 2006).

\section{Sosyal Provizyon Ölçeği}

$\mathrm{Bu}$ araştırmada lise öğrencilerinin sosyal destek algılarını ölçmek amacıyla sosyal provizyon ölçeği kullanılmıştır. Bu ölçek Weiss (1974) tarafından tanımlanan 6 sosyal destek provizyonunu temel alarak Russel ve arkadaşları tarafından (1984) geliştirilmiştir. Ölçeğin Türkçe uyarlama çalışmaları Duru ve Balkıs (2007) tarafından gerçekleştirilmiş, 24 madde olan ölçek uyarlama ve gerçekleştirilen çalışmalar sonucunda 20 maddeye indirilerek tek boyutlu dörtlü likert formda uygulanmaktadır. Ölçeğin iç tutarlık katsayısı .90 olarak bulunmuştur. Test-tekrar test güvenirliği için yapılan analiz sonuçlarına göre, yapılan iki uygulama arasındaki Pearson Korelasyon Katsayısı, $r=.75, \mathrm{p}<.001$ düzeyinde anlamlı bulunmuştur.

\section{Verilerin Analizi}

$\mathrm{Bu}$ araştırmanın çalışma gurubunu 2014 Karaman ilinde öğrenim gören lise öğrencileri oluşturmaktadır. Araştırma kapsamında 262 ailesi boşanmış, 322 ailesi birlikte yaşayan olmak üzere toplam 584 öğrenciye ulaşılmıştır. Araştırmada veri toplama aracı olarak kişisel bilgi formu, Gürgan'ın (2006) geliştirdiği yılmazlık ölçeği, Russel ve arkadaşları (1984) tarafından geliştirilen ve Duru ve Balkıs (2007) tarafından Türkçeye uyarlanan sosyal provizyon ölçeği kullanılmıştır. Bu araştırma genel tarama modelinin alt türü olan ilişkisel tarama modeli ile gerçekleştirilmiştir araştırma sonuçlarının analizinde korelasyon analizi ve $\mathrm{T}$ testi SPSS programı kullanılarak gerçekleştirilmiştir.

\section{Etik}

Bu çalışma 1964 Helsinki deklarasyonuna uygun olarak yürütülmüştür. Ayrıca çalışmaya katılan bütün katılımcılardan aydınlatılmış onamları alınmıştır ve katılımcıların gönüllük ilkesiyle veriler toplanmıştır. Bu kapsamda etik kurallara uyulduğunu taahhüt ederiz.

\section{BULGULAR}

Ebeveynleri boşanmış lise öğrencilerinin Yılmazlık Ölçeğinin alt boyutlarından aldıkları puanlar ile Sosyal Provizyon Ölçeğinden aldıkları puanların ilişkisi incelendiğinde, alt ölçekler ile sosyal provizyon arasındaki korelasyonun .353 ile .565 arasında değiştiği ve her bir alt boyutta orta düzeyde, pozitif yönlü anlamlı ilişki olduğu sonucu bulunmuştur (ayrıntılar için Tablo 1'e bakınız). 


\section{Tablo 1.}

Ebeveynleri Boşanmış Lise Öğrencilerinin Yılmazlık Düzeyleri Ile Sosyal Provizyon Algıları Arasındaki Illişki

\begin{tabular}{ll}
\hline Yılmazlık alt boyutlar & Sosyal Provizyon \\
Güçlü Olma & $.540 * *$ \\
Girişimci Olma & $.565 * *$ \\
İyimser Olma & $.536 * *$ \\
İlişki Kurma & $.443 * *$ \\
Öngörülü Olma & $.440 * *$ \\
Amaca Ulaşma & $.513 * *$ \\
Lider Olma & $.353 * *$ \\
Araştırıcı Olma & $.407 * *$ \\
$* * \mathrm{p}<.01$ & \\
$* \mathrm{p}<.05$ & \\
\hline
\end{tabular}

Ebeveynleri boşanmamış lise öğrencilerinin Yılmazlık Ölçeğinin Güçlü Olma, Girişimci Olma, İyimser Olma, İlişki Kurma, Amaca Ulaşma, Lider Olma alt boyutlarından aldıkları puanlar ile Sosyal Provizyon Ölçeğinden aldıkları puanların ilişkisi incelendiğinde, bu alt ölçekler ile sosyal provizyon arasındaki korelasyonun .343 ile .447 arasında değiştiği ve her bir alt boyutta orta düzeyde, pozitif yönlü anlamlı ilişki olduğu sonucu bulunmuştur ayrıca Öngörülü Olma ve Araştırıcı olma alt boyutları. Ayrıca Sosyal Provizyon Ölçeğinden aldıkları puanların ilişkisi incelendiğinde, bu alt ölçekler ile sosyal provizyon arasındaki korelasyonun sırasıyla .209 ile .292 olduğu ve düşük düzeyde, pozitif yönlü anlamlı ilişki sonucu bulunmuştur (ayrıntılar için Tablo 2'ye bakınız).

\section{Tablo 2.}

Ebeveynleri Boşanmamış Lise Öğrencilerinin Yılmazlık Düzeyleri İle Sosyal Provizyon Algıları Arasındaki Ilişki

\begin{tabular}{ll}
\hline Yılmazlık alt boyutlar & Sosyal Provizyon \\
Güçlü Olma & $.447 * *$ \\
Girişimci Olma & $.425 * *$ \\
İyimser Olma & $.427 * *$ \\
İlişki Kurma & $.360 * *$ \\
Öngörülü Olma & $.209 * *$ \\
Amaca Ulaşma & $.422 * *$ \\
Lider Olma & $.343 * *$ \\
Araştırıcı Olma & $.292 * *$ \\
& \\
$* * \mathrm{p}<.01$ & \\
$* \mathrm{p}<.05$ & \\
\hline
\end{tabular}

Tablo 3 incelendiğinde; ebeveynleri boşanmamış lise öğrencilerinin sosyal provizyon puan ortalaması 61.54, ebeveynleri boşanmış öğrencilerin sosyal provizyon puan ortalamaları ise 61.32 olduğu görülmektedir. Ebeveynleri boşanmamış ve ebeveynleri boşanmış lise öğrencilerinin puan ortalamaları arasındaki t değeri .26 olarak hesaplanmıştır. Bu sonuç .05 manidarlık düzeyinde anlamlı bulunmamıştır. 


\section{Tablo 3.}

Ebeveynleri Boşanmamış ve Ebeveynleri Boşanmış Olma Durumuna Göre Lise Öğrencilerinin, Sosyal Provizyon Algı Puanları Arasındaki T Testi Karşılaştırmasına İlişkin Bulgular

\begin{tabular}{lllllll}
\hline & Aile Durumu & $\mathbf{n}$ & $\bar{X}$ & $\mathbf{S}$ & $\mathbf{t}$ & $\mathbf{p}$ \\
Sosyal Provizyon algıları & Boşanmamış & 322 & 61.54 & 9.40 & .26 & $\mathrm{P}>.05$ \\
& Boşanmış & 262 & 61.32 & 10.30 & &
\end{tabular}

Tablo 4 incelendiğinde; lise öğrencilerinin y1lmazlık ölçeğinin Güçlü Olma alt boyutunda, ebeveynleri boşanmamış ve boşanmış lise öğrencilerinin puan ortalaması sırasıyla 63.80 ve 64.99 , puan ortalamaları arasındaki t değeri -1.15 olarak hesaplanmıştır. Bu sonuç .05 manidarlık düzeyinde anlamlı bulunmamıştır. Girişimci Olma alt boyutunda, ebeveynleri boşanmamış ve boşanmış lise öğrencilerinin puan ortalaması sırasıyla 33.04 ve 33.27, puan ortalamaları arasındaki t değeri -.41 olarak hesaplanmıştır. Bu sonuç .05 manidarlık düzeyinde anlamlı bulunmamıştır. İlişki Kurma alt boyutunda, ebeveynleri boşanmamış ve boşanmış lise öğrencilerinin puan ortalaması sırasıyla 15.06 ve 15,39, puan ortalamaları arasındaki t değeri 1.04 olarak hesaplanmıştır. Bu sonuç .05 manidarlık düzeyinde anlamlı bulunmamıştır. Öngörülü Olma alt boyutunda, ebeveynleri boşanmamış ve boşanmış lise öğrencilerinin puan ortalaması sırasıyla 10.26 ve 10.56, puan ortalamaları arasındaki t değeri - 1.50 olarak hesaplanmıştır. Bu sonuç .05 manidarlık düzeyinde anlamlı bulunmamıştır. Amaca Ulaşma alt boyutunda, ebeveynleri boşanmamış ve boşanmış lise öğrencilerinin puan ortalaması sırasıyla 15.00 ve 15.36 , puan ortalamaları arasındaki t değeri -1.24 olarak hesaplanmıştır. $\mathrm{Bu}$ sonuç .05 manidarlık düzeyinde anlamlı bulunmamıştır. Lider Olma alt boyutunda, ebeveynleri boşanmamış ve boşanmış lise öğrencilerinin puan ortalaması sırasıyla 18.39 ve 18.45, puan ortalamaları arasındaki $\mathrm{t}$ değeri -.18 olarak hesaplanmıştır. Bu sonuç .05 manidarlık düzeyinde anlamlı bulunmamıştır. Araştırıcı Olma alt boyutunda, ebeveynleri boşanmamış ve boşanmış lise öğrencilerinin puan ortalaması sırasıyla 7,74 ve 7,93, puan ortalamaları arasındaki t değeri -1.19 olarak hesaplanmıştır. Bu sonuç .05 manidarlık düzeyinde anlamlı bulunmamıştır. İyimser Olma alt boyutunda, ebeveynleri boşanmamış ve boşanmış lise öğrencilerinin puan ortalaması sırasıyla 21.62 ve 18.20, puan ortalamaları arasındaki t değeri 8,98 olarak hesaplanmıştır. Bu sonuç .05 manidarlık düzeyinde anlamlıdır. Puan ortalamalarına göre ebeveynleri boşanmamış lise öğrencilerinin iyimser olma durumları daha yüksektir. 
Tablo 4.

Ebeveynleri Boşanmamışv ve Ebeveynleri Boşanmış Olma Durumuna Göre Lise Öğrencilerinin, Yılmazlık Ölçeği Alt Boyutları Puanları Arasındaki T Testi Karşılaştırmasına İlişkin Bulgular

\begin{tabular}{|c|c|c|c|c|c|c|}
\hline Yılmazlık & $\begin{array}{l}\text { Aile } \\
\text { Durumu }\end{array}$ & $\mathbf{n}$ & $\bar{X}$ & $\mathbf{S}$ & $\mathbf{t}$ & $\mathbf{P}$ \\
\hline \multirow[t]{2}{*}{ Güçlü Olma } & Boşanmamış & 322 & 63.80 & 11.63 & -1.15 & $\mathrm{P}>.05$ \\
\hline & Boşanmış & 262 & 64.99 & 6.76 & & \\
\hline Girişimci Olma & Boşanmamış & 322 & 33.04 & 6.76 & -.41 & $\mathrm{P}>.05$ \\
\hline İyimser Olma & $\begin{array}{l}\text { Boşanmış } \\
\text { Boşanmamış }\end{array}$ & $\begin{array}{l}262 \\
322\end{array}$ & $\begin{array}{l}33.27 \\
21.62\end{array}$ & $\begin{array}{l}6.54 \\
4.57\end{array}$ & 8.98 & $\mathrm{P}<.01$ \\
\hline \multirow[t]{2}{*}{ İlişki Kurma } & $\begin{array}{l}\text { Boşanmış } \\
\text { Boşanmamış }\end{array}$ & $\begin{array}{l}262 \\
322\end{array}$ & $\begin{array}{l}18.20 \\
15.06\end{array}$ & $\begin{array}{l}4.58 \\
3.59\end{array}$ & -1.04 & $\mathrm{P}>.05$ \\
\hline & $\begin{array}{l}\text { Boşanmış } \\
\text { Boşanmamış }\end{array}$ & $\begin{array}{l}262 \\
322\end{array}$ & $\begin{array}{l}15.39 \\
10.26\end{array}$ & $\begin{array}{l}3.93 \\
2.38\end{array}$ & -1.50 & $\mathrm{P}>.05$ \\
\hline Öngörülü Olma & $\begin{array}{l}\text { Boşanmış } \\
\text { Boşanmamış }\end{array}$ & $\begin{array}{l}262 \\
322\end{array}$ & $\begin{array}{l}10.56 \\
15.00\end{array}$ & $\begin{array}{l}2.50 \\
3.37\end{array}$ & -1.24 & $\mathrm{P}>.05$ \\
\hline Amaca Ulaşma & $\begin{array}{l}\text { Boşanmış } \\
\text { Boşanmamış }\end{array}$ & $\begin{array}{l}262 \\
322\end{array}$ & $\begin{array}{l}15.36 \\
18.39\end{array}$ & $\begin{array}{l}3.51 \\
3.85\end{array}$ & -.18 & $\mathrm{P}>.05$ \\
\hline \multirow[t]{2}{*}{ Araştırıcı Olma } & $\begin{array}{l}\text { Boşanmış } \\
\text { Boşanmamış }\end{array}$ & $\begin{array}{l}262 \\
322\end{array}$ & $\begin{array}{l}18.45 \\
7.74\end{array}$ & $\begin{array}{l}3.86 \\
1.79\end{array}$ & -1.19 & $\mathrm{P}>.05$ \\
\hline & Boşanmış & 262 & 7.93 & 1.95 & & \\
\hline
\end{tabular}

\section{TARTIŞMA ve SONUÇ}

Ebeveynleri boşanmış lise öğrencilerinin Yılmazlık Ölçeğinin Güçlü Olma alt boyutu, Girişimci Olma alt boyutu, İyimser Olma alt boyutu, İlişki Kurma alt boyutu, Öngörülü Olma alt boyutu, Amaca Ulaşma alt boyutu, Lider Olma alt boyutu, Araştırıcı Olma alt boyutları ile Sosyal Provizyon Algıları arasında orta düzeyde, pozitif yönlü anlamlı ilişki bulunmuştur. Terzi (2008) tarafindan üniversite öğrencileri ile gerçekleştirilen çalışmada yılmazlık ile algılanan sosyal destek arasında anlamlı bir ilişki olduğu sonucuna ulaşılmıştır. Terzi' nin elde etmiş olduğu sonuç; yılmazlık ve algılanan sosyal destek arasındaki pozitif ilişkinin sonuçları açısından bu araştırmadan elde edilen bulguları destekleyici bulunmaktadır. Ebeveynleri boşanmış lise öğrencilerinin yılmazlık ve sosyal destek algıları arasında bulunan pozitif yönlü anlamlı ilişki ile ilgili olarak bu bireyler anne ya da babanın olmamasından kaynaklı daha güçlü olmak, ayakta kalmak için daha çok sorumluluk almak zorunda olmakta ve azami çaba ve gayret göstermekte olabilirler. Ayrıca bu bireylerin çevresindeki diğer insanlar (birlikte yaşadığı anne ya da baba, diğer akrabalar, öğretmenler ve diğer sosyal çevre) bu gençlere tek ebeveynli olmalarından kaynaklı destekleyici, koruyucu ve kollayıcı ilişkiler içerisinde bulundukları için sosyal destek ve sosyal destek ağının niteliksel ve niceliksel olarak varlığ başlarına gelmeleri gerektiği için yılmazlığın diğer alt boyutları olan girişimcilik, lider olma ve amaca ulaşma alanlarında daha gayretli ve istekli olmaları da muhtemeldir. Bu bireylerin sosyal destek algılarının ve yılmazlık düzeylerinin ilişkili ve yüksek olmasının bir diğer sebebi olarak; toplumumuzdaki insanların tek ebeveynli çocuklara ve gençlere karşı gösterilen hassasiyet ve pozitif ayrımcılıklardan kaynaklandı̆̆ yorumu yapılabilir.

Ebeveynleri birlikte olan lise öğrencilerinin Yılmazlık Ölçeğinin Güçlü Olma alt boyutu, Girişimci Olma alt boyutu, İyimser Olma alt boyutu, İlişki Kurma alt boyutu, Amaca Ulaşma alt boyutu, Lider Olma alt boyutları ile Sosyal Provizyon Algıları arasında orta düzeyde, pozitif yönlü anlamlı ilişki bulunmuştur. 
Yılmazlık Ölçeğinin Araştırıcı Olma ve Öngörülü Olma alt boyutu ile Sosyal Provizyon Algıları arasında düşük düzeyde, pozitif yönlü anlamlı ilişki bulunmuştur. Bu araştırma ile dolaylı yönden ilgili araştırma pozitif duygularla ilgili olarak Cohn ve arkadaşları (2009) tarafından yapılmıştır. Araştırma sonucunda, üniversite öğrencilerinin günlük pozitif duygularının bir kişilik özelliği olarak yılmazlığı ve yaşam doyumunu yordadığı saptanmıştır. Yılmazlıktaki değişikliğin de pozitif duygu ve yaşam doyumuna aracılık ettiği bulunmuştur. Yılmazlık ve pozitif duygular da yaşam doyumu ile ilişkili bulunmuştur. Bu sonuç doğrultusunda yapmış olduğumuz araştırma Cohn ve arkadaşlarının (2009) yapmış olduğu araştırmayı desteklemektedir. Algılanan sosyal destek kavramının bireylere sağlamış olduğu duygusal boyut yaşam doyumuyla ilişkili bir kavram olarak düşünüldüğü takdirde araştırmadan elde edilen bulgu ile ilgili literatürün birbirini desteklediği görülmektedir. Terzi’ nin (2008) üniversite öğrencileri ile gerçekleştirdiği sosyal destek ve yılmazlık çalışması da sonuç ve bulgular anlamında bu araştırmadan elde edilen sonuçlar birbirini destekler niteliktedir. Ayrıca Arastaman ve Balcının 2013 yılında lise öğrencileri ile sosyal destek faktörleri arasında yer alan aile ve arkadaş desteğinin yılmazlık üzerine etkisine ilişkin yapılan çalışma bulgularında bu iki destek türünün yılmazlığın önemli yordayıcıları olduğu sonuçlarına ulaşılmıştır. Bu anlamda elde edilen bulgular bu çalışmadan elde edilen sonuçları destekler niteliktedir.

$\mathrm{Bu}$ araştırmadan elde edilen sonuçlar yılmazlık ve algılanan sosyal desteğin arasında orta düzeyde pozitif yönlü bir ilişki olduğunu göstermektedir. Bunu destekleyen bir çalışma olarak; üniversiteye hazırlanan ergenlerle yapılan başka bir çalışmada Dayığlu (2008), üniversiteye hazırlanan adayların yılmazlık destek faktörlerini incelemiştir. Araştırmada yüksek düzeyde öğrenilmiş güçlülük ve algılanan sosyal destek puanlarına sahip olan adayların yılmazlık puanları da daha yüksek bulunmuştur. Ayrıca Demir ve Aliyev'in (2019) Türkiye'deki Suriyeli üniversite öğrencilerinde yapmış olduğu bir başka çalışmada sosyal desteğin yılmazlık üzerinde koruyucu faktör olduğu görülmüştür.

Sosyal destek ile ilgili literatür incelendiğinde sosyal desteğin genellikle aile üyeleri tarafından sağlanan ve arkadaşlar tarafından sağlanan destek üzerinde yoğunlaştığı her iki desteğin nasıl algılandığının farklı sonuçları olabileceği (Crohan\&Antonucci, 1989; Rook, 1987; Seeman\& Berkman, 1988) ve sosyal desteğin kişinin ruh sağlığını ve fizyolojik sağlığını etkileyebileceği görülmüştür (Gallant ve diğ., 2007; Matt\& Dean, 1993; Potts, 1997; Shor ve diğ., 2013). İlgili çalışmalar incelendiğinde sosyal desteğin bireyin ruh sağlı̆̆ ve fizyolojik durumlarıyla ilişkili ve olumlu etkilerinin olacağ1 görülmüştür. Ancak bu araştırmada elde ettiğimiz bulgular sosyal destek algısının bireylerin ayrıca arkadaş desteği, fiziksel, araçsal ve parasal destek türleriyle de ilişkili olduğu düşünülürse sosyal destek algısının doğrudan ve sadece anne babaların birlikte ya da boşanmışlık durumlarına göre oluşmadığı ve algılanmadığı yorumu yapılabilir.

$\mathrm{Bu}$ araştırmanın diğer bir boyutunu oluşturan sosyal destekle ilgili araştırmalara baktığımızda; Markward ve arkadaşları (2003) kendi kişisel özelliklerine dayanarak, yetişkinlerden gelen farklı sosyal destek ihtiyacı ya da deneyimi üzerine araştırma yapmışlardır. Bu araştırma genç insanların kendilerine sevme ve sevilme hissini veren ve duygusal destekten faydalandıklarını göstermektedir (Akt. Fagg ve diğ., 2008). Sosyal desteğin yalnızca aileden sağlanan bir destek türü olmadığını, ancak aileden sağlanan sosyal desteğin daha etkili olduğunu gösteren bir başka araştırmaya göre; aile üyelerinden sağlanan desteğin arkadaşlardan sağlanan destekten daha faydalı olduğu bulunmuştur (Shor ve diğ., 2013). İlgili araştırmayı destekleyen bir başka araştırmaya göre; bazı akademisyenler, aile üyelerinin (özellikle kardeşler, çocuklar ve eşler; bakınız Wellman ve Wortley, 1989,1990) pratik görevlerde ve fiziksel ihtiyaçlarda yardımcı olarak ve hastalık dönemlerinde yardım sağlayarak, araçsal destek sağlama konusunda daha önemli oldukları üzerine bir araştırma yapmışlardır (Akt. Shor ve diğ., 2013). Aileden sağlanan sosyal desteğin etkililiği ile ilgili yapılan bir başka araştırma; Aile üyelerinin bağlanma duygusunu daha yüksek seviyede hissetmeleri ve fiziksel olarak daha yakın olmaları (hatta sık sık aynı hane içinde yaşamaları) bireylerin strese neden olan sorunları çözmeye daha meyilli olmalarını sağlamaktadır. (Dupertuis ve di ̆., 2001; LaGreca ve diğ., 1995; Primomo ve diğ., 1990; Prohaska\&Glasser, 1996; Thoits, 2011; Shor ve diğ., 2013). Cattell ve Herring (2002) arkadaşalar ve aileden sağlanan sosyal destek ile ilgili; kent konutlarında iletişim kuran gençler için, bu 
ilişkilerden aldıkları duygusal destekten dolayı yıllar boyu süren arkadaşlık bağları gerçekten önemli olurken, aile ve arkadaşlarından gelen desteğin de onların günlük yaşamları için çok önemli olduğunu rapor ederler (Akt. Fagg ve diğ., 2008). Diğer bir açıdan ele alındığında Sosyal desteğin ruh sağlığı ve iyi oluş (esenlik) üzerinde 'Doğrudan' rolü olduğu ve stresli yaşam olayları ve zor koşullar için dolaylı olarak 'tamponlama' etkileri olduğu düşünülmektedir (Cohen\&Wills, 1985; Stansfeld, 1998; Fagg ve diğ., 2008).Ayrıca, araştırmalar diğerlerinden daha fazla sosyal destek algılayan insanların daha çok yaşam doyumuna sahip olduklarını göstermiştir (Montes-Berges\&Augusto, 2007; Gallagher\& Vella-Brodrick, 2008; Kong \&You, 2011; Kong ve diğ. 2012). Literatür sonuçları ve bu araştırmadan elde edilen bulgular her ne kadar algılanan sosyal desteğin temelde aileden geldiğini gösterse de sosyal destek algısının yalnızca aileden sağlanan destekten oluşmadığı ve bundan dolayı sadece ailenin birliktelik ve boşanmışlık durumuna göre şekillenmeyeceği yorumu yapılabilir.

Ebeveynleri boşanmamış ve ebeveynleri boşanmış lise öğrencilerinin y1lmazlık ölçeğinin Güçlü Olma, Girişimci Olma, İlişki Kurma, Öngörülü Olma, Amaca Ulaşma, Lider Olma, Araştırıcı Olma alt boyutlarında puan ortalamaları ve t değerleri arasında anlamlı düzeyde fark bulunmamıştır. Elde edilen sonuçlar farklılaşma olmadığını göstermektedir.

Ebeveynleri boşanmamış ve ebeveynleri boşanmış lise öğrencilerinin yılmazlık ölçeğinin bir diğer alt boyutu olan İyimser Olma alt boyutunda puan ortalamaları ve t değerleri arasında anlamlı düzeyde fark bulunmuştur. Puan ortalamalarına göre ebeveynleri boşanmamış lise öğrencileri, ebeveynleri boşanmış lise öğrencilerine göre iyimser olma durumları daha yüksektir. Elde edilen sonuçlar farklılaşma olduğunu göstermektedir. Ebeveynleri birlikte olan lise öğrencilerinin daha iyimser olmalarının nedeni olarak bu bireylerin anne babaları birlikte olduğu için tek ebeveynli bireylere göre kendilerini daha güvende hissetmeleri daha az karamsarlık duygusu yaşamaları ve daha az kötümser olmalarından kaynaklı olduğu düşünülmektedir. Ünüvar' ın aktardığına göre, Tusaie ve arkadaşları (2007), 624 ABD’li yaşları 18-14 arasında değişen kırsal kesimde yaşayan ergenlerle psiko-sosyal yılmazlık üzerine çalışma yapmışlardır. Yapılan çalışmada psiko-sosyal yılmazlığın yaygın noktasını açıklamak hedeflenmiştir. Kırsal kesimlerde yaşayan ergenlerde cinsiyet, yaş, iyimserlik, aileden ve arkadaşlardan desteğin algılanması ile psiko-sosyal yılmazlık arasındaki ilişkiler incelenmiştir. Çalışma sonuçlarına göre psiko-sosyal yılmazlık, iyimser olma, bilişsel faktörler, algılanan sosyal destek (aile desteği), kötü yaşam olayları, yaş ve cinsiyet tarafından büyük ölçüde ön görülmüştür. Ayrıca Arı ve Çarkıt (2020) tarafından gerçekleştirilen meta analiz çalışmada; Özcan'ın (2005) lise öğrencileriyle gerçekleştirdiği çalışmada cinsiyete göre yılmazlık düzeylerinin farklılaşmadığı sonuçlarına ulaşılmıştır. Tusaie ve arkadaşlarının (2007) bulgularına göre algılanan sosyal destek ve iyimser olma psiko-sosyal yılmazlık seviyesi üzerinde etkili olmuştur. İlgili araştırma ile bu araştırmadan elde edilen ebeveynleri boşanmamış lise öğrencileri, ebeveynleri boşanmış lise öğrencilerine göre daha iyimser olmaları açısından destekler niteliktedir. Özcan (2005) lise öğrencileriyle yapmış olduğu araştırmada, lise öğrencilerinin sahip oldukları yılmazlık özelliklerini ve koruyucu faktörlerini ebeveynlerinin birlikte - ayrı olma durumlarına ve öğrencilerin cinsiyetlerine göre incelemiştir. Bu araştırma anne babası birlikte ve boşanmış 152 öğrenci ile gerçekleştirilmiştir. $\mathrm{Bu}$ araştırma bulgularına göre, ailesi birlikte yaşayan lise öğrencilerinin yılmazlık özelliklerinin ebeveynleri boşanmış lise öğrencilerine kıyasla, daha yüksek olduğu sonucuna ulaşılmıştır. Ayrıca öğrencilerin cinsiyetlerine göre anlamlı bir farklı1ık bulunmamıştır. Özcan' ın yapmış olduğu araştırma sonuçlarına göre ebeveynleri birlikte olan lise öğrencilerinin yılmazlık düzeyleri ebeveynleri boşanmış lise öğrencilerinin yılmazlık düzeyinden daha yüksek bulunmuştur ancak bu araştırmadan elde edilen bulgular bu şekilde bir farklılaşma olmadığını göstermektedir. Friborg ve arkadaşlarının (2005) yetişkinler için yılmazlık ölçeği kullanarak yaptıkları araştırmada, askeri yüksek okul öğrencilerinin kişilik, bilişsel yetenekler ve sosyal zekâ ilişkilerini incelenmişlerdir. Araştırma sonucunda, bütün yllmazlık özelliklerinin duygusal durum, sosyal yeterlilik, dışa dönüklük, uyumluluk ve sosyal beceriler olmak üzere beş büyük kişilik özelliğiyle ilgili olduğu görülmüştür. Ancak ilginç bir sonuç olarak yılmazlığın aile bütünlüğü ve bilişsel yeteneklerle ilişkili 
olmadığı sonucuna ulaşılmıştır (Demirbaş, 2010). İlgili araştırmadan elde edilen sonuçlar ile bu araştırmadan elde edilen sonuçlar iyimser olma alt boyutu dışında yılmazlığın aile bütünlüğü ile ilişkili olmadığ1 sonucunu desteklemektedir.

$\mathrm{Bu}$ araştırmayla dolaylı ilgisi olan bir başka araştırmaya göre, Karaırmak (2007) öz güveni yüksek olan kişilerin daha iyimser ve umutlu olarak yaşama baktıkları görülmüştür. Umut taşıyan kişilerin daha çok pozitif duygu yaşadıkları bu nedenle daha yılmaz oldukları sonucuna ulaşılmıştır. Ayrıca, iyimser olan kişilerin daha fazla yaşam doyumu hissettikleri ve psikolojik olarak daha yılmaz oldukları bulunmuştur). Bu açıdan ele alındığında ebeveynleri birlikte yaşayan ergenlerin ebeveynleri ayrı olan ergenlere göre daha iyimser oldukları sonucunu bulduğumuz araştırma ilgili araştırmayı destekler niteliktedir.

Araştırma bulgularına göre ebeveynleri boşanmış lise öğrencilerinin Yılmazlık Ölçeğinin Güçlü Olma, Girişimci Olma, İyimser Olma, İlişki Kurma, Öngörülü Olma, Amaca Ulaşma, Lider Olma, Araştırıcı Olma alt boyutları ile Sosyal Provizyon Algıları arasında orta düzeyde, pozitif yönlü anlamlı ilişki bulunmuştur. Aynı sonuçlar ebeveynleri birlikte olan lise öğrencileri içinde geçerlidir. Ebeveynleri birlikte olan lise öğrencilerinin de Y1lmazlık ile Sosyal Provizyon Algıları arasında orta düzeyde, pozitif yönlü anlamlı ilişki bulunmuştur. Ayrıca araştırmanın diğer bir sonucuna göre ebeveynleri boşanmamış ve ebeveynleri boşanmış lise öğrencilerinin sosyal provizyon algıları ergenlerin ebeveynlerinin boşanmış ya da boşanmamış olma durumlarına göre farklılaşmamaktadır. Araştırmanın diğer sonucuna göre Ebeveynleri boşanmamış ve ebeveynleri boşanmış lise öğrencilerinin yılmazlık ölçeğinin Güçlü Olma, Girişimci Olma, İlişki Kurma, Öngörülü Olma, Amaca Ulaşma, Lider Olma, Araştırıcı Olma alt boyutlarında ebeveynlerin birliktelik ve boşanmışlık durumlarına göre farklılaşma bulunamamıştır. Ancak yılmazlık ölçeğinin İyimser Olma alt boyutunda ebeveynleri birlikte olan lise öğrencilerinin ebeveynleri ayrı oranlara kıyasla daha iyimser oldukları, daha az karamsarlık yaşadıkları görülmektedir.

$\mathrm{Bu}$ çalışma sonucunda ileride yapılabilecek araştırmalar için yararlı olabileceği varsayılan öneriler: Ülkemizde yılmazlık ve algılanan sosyal destek konularında gerçekleştirilen çalışmaların niceliksel ve niteliksel anlamda arttırılmasının, bu çalışmanın farklı bölgelerde, farklı yaş gruplarında, yılmazlık ve algılanan sosyal destek ile yakından ilişkili diğer kavramlarla ve değişkenlerle çalışılmasının alan yazına katkı sağlayacağı düşünülmektedir. Ayrıca davranışsal ve etkileşim anlamında ergenlerde yılmazlık düzeylerinin attırılabilmesi, koruyucu faktörlerin etkinliğinin arttırılması için bireylerin inisiyatif almaları teşvik edilmeli, sorunların üstesinden gelemedikleri durumlarda destek sağlandığında yılmazlık düzeylerinin gelişimine katkı sağlanabilecektir. Ebeveynleri boşanmış çocukların yakınları daha hassas ve duyarlı olmalıdır. Çocuklara boşanma ile ilgili olumsuz yükleme (suçlama vb.) yapılmamalıdır. Ayrıca ayrılan ebeveynler çocuklara karşı birbirlerini suçlamamalıdır. Ebeveynler boşanma süreci gerçekleştikten sonra çocuklar üzerinden birbirlerine olumsuz göndermelerde, yönlendirmelerde bulunmamalıdır. Destekleme ve eğitim programları bağlamında stresin bireyin dayanıklılık düzeyine olumsuz etkileri göz önüne alınarak bireylere stresle baş etme becerileri kazandırılarak bireylerin psikolojik dayanıklılıkları desteklenebilir. Çocukların risk altında yetişmesi onların sosyal destek algılarını olumsuz etkilemekte ve yılmazlık algılarını da düşürmektedir $\mathrm{Bu}$ bağlamda aile eğitim programları ile ebeveynlerin eğitimlere alınması, sağlıklı ebeveyn rolleri ve çocuk yetiştirme konularında bilinçlendirilmesi de destekleyici faktörler arasındadır. Boşanma durumlarında hem ebeveynlere hem de çocuklara boşanma sonrası uyum, iyileştirici müdahaleler ve krize müdahale kapsamında yapılan sosyal, psikolojik destek çalışmaları dayanıklılık ve bireylerin sosyal destek algılarının güçlendirilmesi bağlamında değerli görülmektedir

\section{KAYNAKÇA}

Akman, Y., Abaslı, K., Polat, Ş. (2018). Duygusal Özerklik, Öğrenci Yılmazlı̆̆ı, Öğretmene Güven ve Problem Çözme Becerilerine Yönelik Alg1 Arasındaki İlişkilerin Öğrenci Görüşlerine Göre İncelenmesi [Students Views on The Relationships Among Emotional Autonomy, Student Resiliency, Student Trust in Teacher and Problem Solving Skills of Students]. GEFAD / GUJGEF 38(3): 9871012. 
Arı, F. A., \& Çarkıt, E. (2020). Investigation of resilience in terms of gender: A meta-analysis study. Research on Education and Psychology (REP), 4(Special Issue), 34-52.

Arastaman, G., Balcı, A. (2013). Lise öğrencilerinin yılmazlık algılarının çeşitli değişkenler açısından incelenmesi [Investigation of High School Students' Resiliency Perception in terms of Some Variables]. Kuram ve Uygulamada Eğitim Bilimleri [Educational Sciences: Theory \& Practice], 13(2), 915-928

Arman, N. (2009). Zihinsel engelli çocuğa sahip anne ve babaların algıladıkları sosyal destek düzeyleri ile tükenmişlik ve kaygl düzeylerinin incelenmesi. [The examination of the anxiety and burnout levels with social supportlevels perceived by mothers and fathers having mentally handicapped children]. (Unpublished Master Thesis), Atatürk University, Institute of Social Sciences, Educational Sciences, Erzurum.

Arslan, Y. (2009). Lise öğrencilerinin algıladıkları sosyal destek ile sosyal problem çözme arasındaki ilişkinin incelenmesi. [The examination of the relationship between high school students perceived social support and their social problem solving levels]. (Unpublished Master Thesis), Selçuk University, Institute of Social Sciences, Educational Sciences, Psychological Counseling and Guidance, Konya.

Boran, E., Sürücü, A., Yılmaz, E. (2018). Üniversite Öğrencilerinin Kendini Toparlama Güçleri ile Mükemmeliyetçilik Algıları Arasındaki İlişkinin İncelenmesi. 2nd International Social and Educational Sciences Symposium - 22-24 October 2018 - Konya

Cohn, M. A., Fredrickson B, L., Brown S.L., Mikels J.A., Conway, A. (2009). Happiness unpacked: Positive emotions increase life satisfaction by building resilience. American Psychological Association. 9 (3), 361-368.

Çiftçi Arıdă̆, N, \& Ünsal Seydooğulları, S. (2019). Lise Öğrencilerinin Yaşam Doyum ve Yılmazlık Düzeylerinin Anne-Baba Tutumlarıyla İlişkisi Açısından İncelenmesi [Investigating life satisfaction and resiliency levels of high school students based on the relation with parental attitudes]. Hacettepe University Journal of Education, 34(4), 1037-1060

Dayığlu, B. (2008). Resilience in university entrance examination applicants: The role of learned resourcefulness, perceived social support, and gender. (Unpublished Master Thesis), Orta Doğu Teknik University, Institute of Social Sciences, Educational Sciences, Ankara.

Demir, Ö.O. \& Aliyev, R., (2019). Resilience among Syrian university students in Turkey. Turkish Journal of Education. 8(1), 33-51

Demirbaş, N. (2010). Yaşamda anlam ve yllmazlık. [Meaning in life and ego-resilience] . (Unpublished Master Thesis), Hacettepe University, Institute of Social Sciences, Educational Sciences, Psychological Counseling and Guidance, Ankara.

Dunst, C.J., Trivette, C.M., Cross, A. H.(1986). Mediating influences of social support: personal, family, child outcomes. American Journal on Mental Deficiency. Jan;90(4):403-17.

Duru, E., Balkıs, M. (2007). Sosyal provizyon ölçeğinin psikometrik özellikleri: geçerlik ve güvenirlik çalışması [Psychometric characteristics of social provision scale: validity and reliability study]. Turkish Psychological Counseling and Guidance Journal, 3(27), 79-90.

Dülger, Ö. (2009). Ergenlerde algılanan sosyal destek ile karar verme davranışları arasındaki ilişkinin incelenmesi. [Correlation between perceived social support and decision making behavior of adolescents]. (Unpublished Master Thesis), Marmara University, Institute of Educational Sciences, Educational Sciences, Psychological Counseling and Guidance, İstanbul.

Fagg, J., Curtis, S., Stansfeld, S., Cattell, V., Tupuola, C., Aephin, A. (2008). Area social fragmentation, social support for individuals and psychosocial health in young adults: Evidence from a national survey in England. Social Science \& Medicine 66(2), 242-254.

Gizir, C. A. (2004). Akademik să̆lamlık: Yoksulluk içinde sekizinci sınıf öğrencilerinin akademik başarılarına katkıda bulunan koruyucu faktörlerin incelenmesi [Academic resilience: an investigation of protective factors contributing to the academic achievement of eight grade students in poverty]. (Unpublished Doctoral Disseration), Middle East Technical University, Institute of Social Sciences, Educational Sciences, Ankara.

Gürgan, U. (2006). Grupla psikolojik danışmanın üniversite ögrencilerinin yılmazlık düzeylerine etkisi. [The Effect of the group program of resiliency level of university students]. (Unpublished Doctoral 
Disseration), Ankara University, Institute of Educational Sciences, Educational Sciences, Psychological Counseling and Guidance, Ankara.

Karaırmak, Ö. (2007). Deprem yaşamış bireylerde psikolojik sağlamlığa etki eden kişisel faktörlerin incelenmesi: Bir model test etme çalışması. [ Investigation of personal qualities contributing to psyhological resilience among earthquake survivors: A model testing study]. (Unpublished Doctoral Disseration), Middle East Technical University, Institute of Social Sciences, Educational Sciences, Ankara.

Kırkıncıoğlu, M. (2003). Çocuk ruh sağlı̆̆ı [child psyche health]. İstanbul: Yapa Press.

Kong, F., Zhao, J., You, X. (2012). Emotional intelligence and life satisfaction in Chinese university students: The mediating role of self-esteem and social support. Personality and Individual Differences, 53(8),1039-1043.

Olsson, C., Bond, L., Burns, J., Brodrick, D., Sawyer, S. (2003). Adolescent resilience: a concept analysis. Journal of Adolescence, 26(1), 1-11.

Onat, G. (2010). Demokratik ve otoriter olarak alglanan ana-baba tutumlarını lise birinci sinif ögrencilerinin yılmazlık düzeyine etkilerinin araştırılması. [The effects of parental attitudes-which are perceived as democratic and authoritarian-on first class of highschool students resiliency level investigated]. (Unpublished Master Thesis), Maltepe University, Institute of Social Sciences, Psychology, Development Psychology, İstanbul.

Öğülmüş, S.(2001). Bir kişilik özelliği olarak yılmazlık. I. Ulusal Çocuk ve Suç Sempozyumu: Nedenler ve Önleme Çalışmaları, Ankara (29-30 Mart).

Özcan, B. (2005). Anne-babaları boşanmış ve anne-babaları birlikte olan lise ögrencilerinin yılmazlık özellikleri ve koruyucu faktörler açısından karşılaştırllması. [ Comparison of high school students whose parents are divorced and whose parents are together in terms of resilience and protective factors]. (Unpublished Master Thesis), Ankara University, Institute of Educational Sciences, Educational Sciences, , Ankara.

Özer, E., Deniz, M. E. (2014). Üniversite Öğrencilerinin Psikolojik Sağlamlık Düzeylerinin Duygusal Zeka Açısından İncelenmesi [An Investigation of University Students' Resilience Level on The View of Trait Emotional EQ ]. Elementary Education Online, 13(4), 1240-1248, 2014.

Peng,L., Zhang, J., Li, M., Li, P., Zhang, Y., Zuo, X., Miao, Y., Xu, Y. (2011). Negative life events and mental health of Chinese medical students: The effect of resilience, personality and social support. Psychiatry Research, 196(1), 138-41.

Shor, E., Roelfs, D., Yogev, T. (2013). The strength of family ties: A meta-analysis and meta-regression ofself-reported social support and mortality. Social Networks,5(4), 626-638

Terzi, Ş. (2008). Üniversite öğrencilerinin yılmazlıkları ve algıladıkları sosyal destek arasındaki ilişki [the relationship between psychological hardiness and perceived social support of university students]. Turkish Psychological Counseling and Guidance Journal,3(29), 1-11.

Ünüvar, A. (2012). Gerçeklik kuramına dayalı psiko-eğitim programının lise öğrencilerinin denetim odağı ve yılmazlık düzeyi üzerindeki etkisinin incelenmesi. [The effect of psychoeducational program based on reality approach on locus of control and resilience of high school students] (Unpublished Doctoral Thesis), Dokuz Eylül University, Institute of Educational Sciences, Educational Sciences, Psychological Counseling and Guidance, İzmir.

\section{EXTENDED ABSTRACT}

Introduction: Looking at the development of the individual, it is seen that the environment and heredity have effects. In this context, the personality and character development of the individual is affected by the social environment in which he/she grew up, the society he / she lives in, culture, biological factors, physiological structure and psychological experiences. The family in which the child grows up, his relationship and communication with his parents; the behaviors of the spouses towards each other and towards the child will affect the child's perceived social support and resilience capacity.

Materials and Methods: In this descriptive study, high school students whose parents were divorced and whose parents were together were examined in terms of their level of resilience and perceived social support. Also, this research was carried out in relational scanning model. In total, 584 students participated in the study and 262 of them have divorced parents and 322 of them have parents living together. In this study, the Resilience Scale developed by 
Gürgan (2006) was used as a data collection tool. Social Support Scale was used for measuring the social support perceptions of high school students. The Social Provisioning Scale was developed by Russell et al. (1984). Correlation analysis and T test were performed by using the SPSS program in the analysis of the research results.

Findings: According to the findings of the relationship between the resilience levels of high school students who have divorced parents and their perceptions of social provision; Being Strong $(r=.540, p<.01)$, Being Entrepreneur $(r=$ $.565, \mathrm{p}<.01)$, Being Optimistic $(\mathrm{r}=.526, \mathrm{p}<.01)$, Relationship $(\mathrm{r}=.443, \mathrm{p}<.01)$, Being Foresight $(\mathrm{r}=.440, \mathrm{p}<.01)$, Reaching the Goal $(r=.513, p<.01)$, Being Leader $(r=.353, p<.01)$, Being Investigative $(r=.353$, $p<.01)$, in each sub-dimension moderate, positive, meaningful relationship was found. Social provision score average of high school students whose parents are not divorced 61.54, social provision score average of high school students whose parents divorced is 61.32 . The $t$ value among the average scores of high school students whose parents were not divorced and whose parents were divorced was calculated as.26. This result was not significant at .05 level of significance. According to findings regarding the comparison of t test between high school students whose parents are divorced and high school students whose parents are not divorced, in the sub-dimensions of the resilience scale; A significant correlation was found only in the sub-dimension of Being Optimistic out of the eight sub-dimensions. High school students whose parents are not divorced are more optimistic than high school students whose parents are divorced.

Discussion: In a study conducted by Terzi (2008) with university students, it was concluded that there was a significant relationship between resilience and perceived social support. The conclusion reached by the Terzi confirms the findings of this study in terms of the results of the positive relationship between psychological resilience and perceived social support. As a result of the study conducted by Cohn et al. (2009), it was determined that the daily positive emotions of university students predicted resilience and life satisfaction as a personality trait. If the emotional dimension provided by the concept of perceived social support to individuals is considered as a concept related to life satisfaction, it is seen that the related literature supports each other. Arastaman and Balc1 (2013) conducted a study on the effect of family and friend support on resilience, which are among the social support factors of high school students. It is concluded that these two types of support are important predictors of resilience. Day1oğlu (2008) examined the resilience support factors of candidates preparing for university. In the study, it was observed that the resilience scores of the candidates with high perception of social support were higher. Demir and Aliyev (2019) in their study with Syrian university students in Turkey, has been shown to be a protective factor on the resilience of social support. In the study conducted by Jew, Green and Kroger (1999) on resilience, it was concluded that relations with family and society, social support and social maturity, self-esteem and focus of control, coping skills are factors related to resilience (as cited in Gürgan, 2006). Resilient children cope more easily in difficult conditions thanks to their successful and strong adaptation skills (Hart et al., 1997; as cited in Ünüvar, 2012 ). According to the study conducted by Peng et al. (2012) with university students, resilience is a protective factor on negative life events and mental health problems. Markward et al. (2003) show that young people benefit from emotional support that gives them a sense of love and being loved. Tusaie et al (2007) according to the results of the study, psycho-social resilience is affected by factors such as optimism, cognitive factors, perceived social support (family support), adverse life events, age and gender. The relevant research results also confirm the relationship between resilience and perceived social support as a result of the findings obtained from this study.

\section{Conclusion and Suggestions:}

- It is thought that the quantitative and qualitative increase in studies on resilience and perceived social support in our country, and working with other concepts and variables closely related to resilience and perceived social support in different regions and different age groups will contribute to the literature.

- Young people should be encouraged to take initiative in order to increase the resilience levels of adolescents in terms of behavioral and interaction and to increase the effectiveness of protective factors.

- In cases where young people cannot overcome their problems, support programs can be created to contribute to the development of their resilience levels.

- Relatives of children whose parents are divorced should be more sensitive.

- Negative attribution (accusation, etc.) about divorce should not be made to children.

- Also, divorced parents should not blame each other against children.

- After the divorce process takes place, parents should not negatively refer to each other through their children.. 